\title{
HUBUNGAN PRAKTIK PEMBERIAN MAKAN DAN PENDIDIKAN IBU TERHADAP PERILAKU PICKY EATER PADA ANAK PRA SEKOLAH
}

\author{
Mita Dwi Puspitasari ${ }^{1}$, Listyaning Eko Martanti ${ }^{2}$, Budi Astyandini ${ }^{3}$ \\ 1,2,3 Jurusan Kebidanan Poltekkes Kemenkes Semarang, Indonesia
}

\begin{abstract}
Perfect brain growth and development occurs when a child is 6 years old, therefore the success of brain growth and development is largely determined before the child is 6 years old. Pre-school children often experience picky eaters furthermore the picky eater is also the result of the play stage of the eating behavior of the closest people, especially the mother. The role of mothers is very influential because mothers have more free time with children, therefore the need for a good mother's role in terms of feeding practices. The purpose of this study was to determine the relationship between feeding practices on picky eater behavior in pre-school children. The sample used was 58 respondents who were selected using purposive sampling. This study was analyzed using the Chi Square test. The results showed that there was a significant relationship between feeding practices and picky eater behavior in pre-school children with the results showing a $p$ value of $0.001<(0.05)$ and there was no significant relationship between mother's education and behavior. picky eaters in pre-school children aged 3-5 years with the results of the study showing a $p$ value of 0.589 $>$ (0.05).
\end{abstract}

Keywords : Feeding practices; Mother's education; Preschool children; Picky eaters 


\section{PENDAHULUAN}

Picky eater pada anak dapat menjadi masalah yang berkaitan dengan status gizi anak, tentunya akan berdampak pada tumbuh kembang anak di masa berikutnya. Salah satu cara untuk mengatasi hal tersebut adalah pemenuhan kebutuhan makanan yang baik. Pada usia prasekolah, terdapat suatu masa yang menyebabkan anak kesulitan untuk makan atau bahkan anak menyukai makanan tertentu yang disukainya secara berlebihan. Perilaku picky eater pada anak seringkali dihubungkan dengan pola pemberian makan dan praktik pemberian makan yang dilakukan oleh ibu. Beberapa kasus seperti berat badan kurang, obesitas, kekurangan mikronutrien dan kenaikan berat badan yang inadekuat merupakan dampak dari picky eater yang berhubungan dengan masalah gizi (Hardianti dkk, 2018).

Berdasarkan hasil Riset Kesehatan Dasar tahun 2018, menjelaskan bahwa berdasarkan prevalensi status gizi buruk dan gizi kurang pada balita dengan Indeks Berat Badan per usia (BB/U) pada anak usia 36-47 bulan di Indonesia, balita yang mengalami gizi kurang sebanyak 15,5\% dan balita yang mengalami gizi buruk sebanyak $3,7 \%$ sedangkan pada usia $48-$ 59 bulan sebanyak balita yang mengalami gizi kurang sebanyak $14,5 \%$ dan balita yang mengalami gizi buruk $3,6 \%$. Persentase gizi buruk pada balita usia 0-
59 bulan di Jawa Tengah adalah sebesar 3,7 \%, sedangkan persentase gizi kurang adalah sebesar 13,68 \%. Berdasarkan Peraturan Menteri Kesehatan Republik Indonesia Nomor 14 tahun 2019 pemerintah menetapkan standar minimal indikator berat badan kurang adalah minimal sebesar $10 \%$, apabila prevalensi dibawah standar minimal yang ditetapkan oleh pemerintah maka bukan merupakan masalah kesehatan masyarakat.

Picky eater bukan hanya menyebabkan masalah gizi kurang, namun obesitas atau kegemukan juga merupakan dampak dari picky eater. Berdasarkan hasil Riskesdas tahun 2018 menunjukan angka kegemukan dan obesitas sebesar $21,8 \%$ kasus ini mengalami kenaikan sebesar $6 \%$ dan lebih tinggi dari target RPJMN 2015-2019 yaitu sebesar $15,4 \%$. Terjadinya masalah gizi sering kali berkaitan dengan gangguan pola makan anak yang terganggu, dan salah satu penyebabnya adalah karena memilih-milih makanan atau picky eater (Mustikasari,2019). Perilaku picky eater atau memilih-milih makanan disebabkan karena anak kurang suka terhadap makanan yang bervariasi, anak belum terbiasa makan makanan selain apa yang disukainya sering kali secara tidak langsung berdampak pada gizi anak (Rufaida \& Wardini Puji Lestari, 2018).

Pada usia prasekolah, anak mulai menirukan kebiasaan dari orang terdekatnya termasuk tentang pola 
makan, tata cara makan, dan jenis makanan yang di konsumsi. Ibu sangat berpegaruh terhadap pola makan anak dan pola makan anak sangat berpengaruh dengan status gizi anak. Biasanya ibu berupaya dengan berbagai cara salah satunya adalah dengan memaksa anak untuk makan, sehingga sering kali anak memiliki persepsi yang kurang menyenangkan akibat pemaksaan yang dilakukan oleh orang tua agar anaknya mau untuk makan (Nadya, 2019).

Berdasarkan studi pendahuluan yang dilakukan oleh peneliti di TK Aisyiyah Bustamil Athfal IV pada tanggal 26 Oktober 2020 dengan wawancara $10 \mathrm{ibu}$, $70 \%$ ibu mengeluhkan anaknya kurang suka terhadap sayur, sering menahan makanan dalam mulut sehingga makan menjadi lama. Sebagian besar ibu mengatakan bahwa anaknya susah makan karena aktif bermain saat pemberian makan sehinggga seringkali menunda untuk makan dan anak lebih cenderung tidak makan secara bervariasi karna hanya makan dengan apa yang disukai anak saja.

\section{METODOLOGI PENELITIAN}

Jenis penelitian ini adalah analitik kuantitatif dengan desain penelitian crosssectional. Penelitian ini dilaksanakan pada bulan Maret 2021 dengan responden penelitian ibu yang memiliki anak pra sekolah usia 3-5 tahun yang bersekolah di TK Aisyiyah Bustamil Atfal IV dan PAUD Lestari V. Variabel independen dalam penelitian ini adalah praktik pemberian makan dan Pendidikan ibu. Variabel dependennya yaitu perilaku picky eater pada anak pra sekolah.

Sampel penelitian ini sebesar 58 responden yang dihitung menggunakan rumus slovin. Pengambilan sampel dilakukan menggunakan teknik purposive sampling yaitu teknik pengambilan sampel dengan pertimbangan kriteria inklusi dan eklusi.

Pengumpulan data dilakukan melalui pengisian kuesioner. Pada lembar kuesioner perilaku picky eater terdiri dari 14 pertanyaan dengan skala likert dan penentuan kategori berdasarkan persentase jumlah skor yang di klasifikasikan menjadi perilaku picky eater apabila responden menjawab $\geq 50 \%$ dari total skor dan tidak picky eater apabila menjawab $<50 \%$ dari total skor. Lembar kuesioner praktik pemberian makan terdiri dari 15 pertanyaan dengan skala likert dan penentuan kategori berdasarkan persentase jumlah skor yang di klasifikasikan menjadi baik apabila menjawab $\geq 76 \%$ dari total skor, kategori cukup apabila menjawab $61-75 \%$ dari total skor, dan kategori kurang apabila menjawab $\leq 60 \%$ dari total skor.

Data yang telah diperoleh di analisis menggunakan uji statistik Chi-Square. Penelitian ini telah dinyatakan layak etik dari komisi etik penelitian Poltekkes Kemenkes Semarang dengan nomor 067/EA/KEPK/2021. 


\section{HASIL PENELITIAN DAN BAHASAN}

Tabel 1. Hubungan praktik pemberian makan terhadap perilaku picky eater

\begin{tabular}{lccc}
\hline Kategori Praktik Pemberian & $\begin{array}{c}\text { Picky Eater } \\
\text { nakan }\end{array}$ & $\begin{array}{c}\text { Tidak Picky Eater } \\
\mathbf{n ~ ( \% )}\end{array}$ & $\boldsymbol{P}$ \\
\hline Baik & $1(7,7 \%)$ & $12(92,3 \%)$ & 0,001 \\
Cukup & $10(38,5 \%)$ & $16(61,5 \%)$ & \\
Kurang & $17(89,5 \%)$ & $2(10,5 \%)$ & \\
\hline Jumlah & $\mathbf{2 8 ( 4 8 , 3 \% )}$ & $\mathbf{3 0 ( 5 1 , 7 \% )}$ & \\
\hline
\end{tabular}

Hubungan Praktik Pemberian Makan dengan Perilaku Picky Eater

Berdasarkan hasil penelitian sebanyak 17 (89,5\%) ibu yang berpengetahuan kurang anaknya mengalami picky eater. Berdasarkan hasil uji statistik didapatkan nilai $p$ value $0,001<\alpha(0,05)$ dengan demikian berarti $\mathrm{Ha}$ diterima karena ada perbedaan proporsi antara praktik pemberian makan dengan perilaku picky eater sehingga dapat disimpulkan ada hubungan yang signifikan antara praktik pemberian makan dengan perilaku picky eater. Adanya ibu yang baik dalam praktik pemberian makan tetapi anaknya mengalami picky eater disebabkan karena ibu tersebut memiliki anak yang aktif bermain sehingga anak seringkali menunda untuk makan yang menyebabkan anak kehilangan nafsu makan dan hal tersebut menyebabkan anak menjadi picky eater.

Sejalan dengan penelitian yang dilakukan oleh Kusumawardhani, dkk (2013) yang dilakukan di Puskesmas Jabon Kabupaten Sidoarjo yang hasilnya menunjukkan adanya pengaruh perilaku makan orang tua dengan perilaku picky eater dengan nilai OR = 10,1 yang artinya orang tua berperilaku memilih milih makanan kemungkinan akan menurunkan perilaku picky eater 10,1 kali lebih tinggi daripada anak yang memiliki orang tua yang tidak memilih-milih makanan. Kemudian, cara pemberian makan juga dapat berpengaruh terhadap perilaku picky eater pada anak, hasil penelitian serupa yang hasilnya di dapatkan nilai $O R$ =13 yang artinya anak dengan praktik pemberian makan kurang baik dapat beresiko mengalami picky eater 13 kali lebih tinggi daripada ibu dengan praktik pemberian makan yang baik.

Menurut penelitian yang dilakukan oleh Astuti, Martanti dan Ariyanti (2020) pola asuh ibu yang kurang baik dalam praktik pemberian makan dapat menyebabkan masalah gizi. Ketika anak susah makan atau picky eater ibu tidak kreatif dalam upaya pemberikan makan, sehingga apabila picky eater terus berlanjut dapat menyebabkan masalah gizi yang apabila tidak ditangani akan menyebabkan gangguan tumbuh kembang dan gangguan reproduksi. Gangguan reproduksi yang disebabkan akibat kurang gizi salah satunya adalah usia menarche yang tertunda. Anak 
dengan gizi cukup lebih cepat mengalami menarch daripada anak dengan gizi kurang (Astyandini 2013).

Perilaku picky eater pada anak prasekolah merupakan hasil play stage atau meniru perilaku makan orang tuanya, sehingga dalam praktik pemberian makan pada anak pra sekolah harus dilakukan dengan penuh hati-hati, kesabaran dan ketekunan. Menurut Astyandini, Khobibah dan Ruspita (2020) dalam sebuah keluarga peran gender berpengaruh terhadap praktik pemberian makan anak. Peran ayah dalam praktik pemberian makan yaitu mengajarkan tata cara makan dengan cara santai seperti bermain dan sebagai role model sehingga anak memiliki kemampuan sosialisasi dan kognitif yang baik (Rohmah,2019). Peran ibu sangat berpengaruh dan sangat penting sebagai bahan percontohan anak tentang bagaimana praktik pemberian makan yang baik, karena ibu memiliki waktu luang yang lebih banyak. Hal ini sejalan dengan penelitian ini dimana ibu dengan kategori baik dalam praktik pemberian makan $71,8 \%$ memiliki anak yang tidak picky eater.

Tahap pembelajaran makan anak dilakukan pada saat usia 1-5 tahun sehingga dalam proses pembelajaran tentang makan, orang tua wajib mengajarkan bagaimana pola makan, praktik pemberian makan serta pola asuh yang baik agar anak dapat menerima dan dapat mempraktikannya dengan baik juga. Gangguan pada proses pembelajaran tersebut, dapat berdampak menjadi kondisi yang menyebabkan kesulitan makan pada anak.

Tabel 2. Hubungan pendidikan ibu terhadap perilaku picky eater

\begin{tabular}{lccc}
\hline \multicolumn{1}{c}{ Pendidikan Ibu } & $\begin{array}{c}\text { Picky Eater } \\
\mathbf{n ~ ( \% )}\end{array}$ & $\begin{array}{c}\text { Tidak Picky Eater } \\
\mathbf{n ~ ( \% )}\end{array}$ & $\boldsymbol{P}$ \\
\hline $\begin{array}{l}\text { Pendidikan Dasar dan } \\
\text { menengah }\end{array}$ & $23(47,9 \%)$ & $25(52,1 \%)$ & 0,589 \\
Pendidikan Tinggi & $5(50,0 \%)$ & $5(50,0 \%)$ & \\
\hline Jumlah & $\mathbf{2 8 ( 4 8 , 3 \% )}$ & $\mathbf{3 0}(\mathbf{5 1 , 7 \% )}$ & \\
\hline
\end{tabular}

\section{Hubungan Praktik Pemberian Makan dengan Perilaku Picky Eater}

Berdasarkan hasil penelitian diperoleh bahwa ada sebanyak 23 $(47,9 \%)$ ibu yang berpendidikan menengah dan dasar anaknya mengalami picky eater. Hasil uji statistik didapatkan nilai $p$ value sebesar $0,589>\alpha(0,05)$ dengan demikian berarti Ho diterima karena tidak ada perbedaan proporsi antara praktik pemberian makan dengan perilaku picky eater sehingga dapat disimpulkan tidak ada hubungan yang signifikan antara praktik pemberian makan dengan perilaku picky eater.

Penelitian serupa dengan penelitian ini juga dilakukan oleh Astuti dan Sulistyowati (2013) yang hasilnya juga 
menyatakan tidak ada hubungan pendidikan ibu dengan status gizi anak dengan $p$ value 0,471 . Hal ini kemungkinan terjadi karena di zaman globalisasi seseorang dengan mudahnya menerima informasi baik dari media elektronik maupun dari media cetak. Dengan adanya smart phone memudahkan semua orang mengakses informasi dengan mudah, yang di latar belakangi juga dengan adanya media sosial yang memudahkan kita dalam hal menerima informasi.

Penelitian ini di dukung oleh penelitian yang dilakukan oleh Pangestika (2018) yang hasilnya dengan uji koefisien determinasi yang hasilnya menunjukkan bahwa sebesar $38,5 \%$ pemanfaatan media sosial sangat berpengaruh terhadap penyebaran informasi. Dengan adanya internet, ibu dengan pendidikan rendah dapat mengakses informasi dengan mudah, sehingga dalam hal ini untuk mendapatkan pengetahuan.

\section{KESIMPULAN}

Terdapat hubungan yang signifikan antara praktik pemberian makan dengan perilaku picky eater pada anak pra sekolah usia 3-5 tahun dan tidak terdapat hubungan yang signifikan antara pendidikan ibu dengan perilaku picky eater pada anak usia pra sekolah usia 3-5. Kejadian picky eater seringkali berkaitan dengan masalah gizi sehingga disarankan pelayanan kebidanan lebih aktif dalam kegiatan posyandu, dengan melibatkan kader serta mengoptimalisasi peran kader dalam memberikan memotivasi dan penyuluhan tentang penanganan terhadap anak yang mengalami picky eater agar tidak terjadi masalah gizi yang serius.

\section{UCAPAN TERIMAKASIH}

Peneliti mengucapkan terimakasih kepada TK Aisyiyah Bustamil Atfal IV dan PAUD Lestari $V$ Cilacap yang telah memberikan izin tempat dalam pelaksanaan penelitian ini serta pihakpihak yang membantu dalam penelitian ini.

\section{DAFTAR PUSTAKA}

[1] R. Hardianti, F. F. Dieny, and H. S. Wijayanti, "Picky Eating dan Status Gizi Pada Anak Prasekolah," J. Gizi Indones. (The Indones. J. Nutr., vol. 6, no. 2, pp. 123-130, 2018.

[2] Kementerian Kesehatan RI Badan Penelitian dan Pengembangan, Hasil Utama Riset Kesehatan Dasar. 2018.

[3] Kementerian Kesehatan RI. Peraturan Menteri Kesehatan Republik Indonesia Nomor 14 Tahun 2019 Tentang Pelaksanaan Teknis Surveilans Gizi, Jakarta. .

[4] A. Mustikasari, "Hubungan Pola Asuh Orangtua dengan Kebiasaan memilih-milih makanan (Picky Eater) pada Anak Prasekolah di TK Aisyiyah 1 Gombong Kabupaten 
Kebumen,"

STIKES

Muhammadiyah Gombong, 2019.

[5] Z. Rufaida and S. Wardini Puji Lestari, "Pola Asuh Dengan Terjadinya Picky Eater (Pilih- Pilih Makanan) Pada Anak Usia 3-6 Tahun Di Dusun Sumberaji Desa Karangjeruk Kecamatan Jatirejo Kabupaten Mojokerto.," J. Issues Midwifery, vol. Vol 2, No, pp. 5654, 2018.

[6] A. Nadya, "Hubungan Kebiasaan Makan Orangtua, Kejadian Picky Eating Terhadap Status Gizi Anak Prasekolah di TK Islam Al-Azhar Padang 2019," STIKES Perintis Padang, 2019.

[7] N. Kusumawardhani, W. Purnomo, R. Hargono, S. N. Hidayati, M. T. Utomo, and S. Andari, "Determinan 'Picky Eater' (Pilih-Pilih Makanan) Pada Anak Usia 1-3 Tahun (Studi Di Wilayah Kerja Puskesmas Jabon Sidoarjo)," J. IIm. Kesehat. Politek. Kesehat. Majapahit Mojokerto, vol. 5, no. 2, pp. 91-119, 2013, [Online]. Available:

http://ejournal.stikesmajapahit.ac.id/ index.php/HM/article/view/83.

[8] N. I. Astuti, L. E. Martanti, and I. Ariyanti, "The Maternal Nutrition and Knowledge Level in Stunting Children," J. Midwifery Sci. Basic Appl. Res., vol. 2, no. 2, pp. 33-37, 2020, [Online]. Available: http://ejournal.poltekkessmg.ac.id/ojs/index.php/JOMISBAR
/article/viewFile/6467/1875.

[9] B. Astyandini, "Perbedaan Usia Menarche dan Pengetahuan tentang Menstruasi antara Remaja Putri di SDN 2 Pegulon dan di SLB Swadaya Kabupaten Kendal," Bul. Penelit. bappeda kabupaten kendal, vol. 3, no. 2, pp. 163-170, 2013, [Online].

Available: https://123dok.com/document/qm01 615y-perbedaan-menarchepegulon-remaja-puteri-grahitaswadaya-kabupaten.htm|\#fulltextcontent.

[10] B. Astyandini, Khobibah, and M. Ruspita, "Peran Gender dalam Hubungan Seks pada Wanita Hamil," J. Kebidanan dan Kesehat. Tradis., vol. 5, no. 2, pp. 67-149, 2020, [Online]. Available: https://jurnalbidankestrad.com/inde x.php/jkk/article/view/158/120.

[11] I. Rohmah, "Hubungan Partisipasi Ayah dengan Praktik Ibu Dalam Pemberian Makan Balita (Jenis,Jumlah,Jadwal)," Universitas Airlangga, 2018.

[12] F. D. Astuti and T. F. Sulistyowati, "Hubungan Tingkat Pendidikan Ibu dan Tingkat pendapatan Keluarga dengan Status Gizi Anak Prasekolah dan Sekolah Dasar di Kecamatan Godean," J. Kesehat. Masy., vol. 7, no. 1, pp. 15-20, 2013,

doi: http://dx.doi.org/10.12928/kesmas.v 7i1.1048. 
[13] N. L. Pangestika, "Pengaruh pemanfaatan media sosial whatsapp terhadap penyebaran informasi pembelajaran di SMA negeri 5 depok," UIN Syarif Hidayatullah, 2018. 